\title{
Distribution of Phosphorylated TrkB Receptor in the Mouse Hippocampal Formation Depends on Sex and Estrous Cycle Stage
}

\author{
Joanna L. Spencer-Segal, ${ }^{1}$ Elizabeth M. Waters, ${ }^{1}$ Kevin G. Bath, ${ }^{2}$ Moses V. Chao,${ }^{4}$ Bruce S. McEwen, ${ }^{1}$ \\ and Teresa A. Milner ${ }^{1,3}$ \\ ${ }^{1}$ Laboratory of Neuroendocrinology, The Rockefeller University, New York, New York 10021, ${ }^{2}$ Department of Psychiatry and ${ }^{3}$ Department of Neurology and \\ Neuroscience, Division of Neurobiology, Weill Cornell Medical College, New York, New York 10065, and ${ }^{4}$ Departments of Cell Biology, Physiology and \\ Neuroscience, and Psychiatry, The Helen L. and Martin S. Kimmel Center for Biology and Medicine, Skirball Institute for Biomolecular Medicine, New York \\ University School of Medicine, New York, New York 10016
}

Tropomyosin-related kinase B receptor (TrkB) is a neurotrophin receptor important for the synaptic plasticity underlying hippocampaldependent learning and memory. Because this receptor is widely expressed in hippocampal neurons, the precise location of TrkB activation is likely important for its specific actions. The goal of this study was to identify the precise sites of TrkB activation in the mouse hippocampal formation and to determine any changes in the distribution of activated TrkB under conditions of enhanced brain-derived neurotrophic factor (BDNF) expression and hippocampal excitability. Using electron microscopy, we localized TrkB phosphorylated at tyrosine 816 (pTrkB) in the hippocampal formation of male and female mice under conditions of naturally low circulating estradiol and naturally high circulating estradiol, when BDNF expression, TrkB signaling, and synaptic plasticity are enhanced. To compare relative amounts of pTrkB in each group, we counted profiles containing pTrkB-immunoreactivity (pTrkB-ir) in all hippocampal subregions. pTrkB-ir was in axons, axon terminals, dendrites, and dendritic spines of neurons in the hippocampal formation, but the majority of pTrkB-ir localized to presynaptic profiles. pTrkB-ir also was abundant in glial profiles, which were further identified as microglia using immunofluorescence and confocal microscopy. Axonal and glial pTrkB-ir and pTrkB-ir in the CA1 stratum radiatum were more abundant in high-estradiol states (proestrus females) than low-estradiol states (estrus and diestrus females and males). These findings suggest that presynaptic TrkB is positioned to modulate estradiol-mediated and BDNF-dependent synaptic plasticity. Furthermore, they suggest a novel role for TrkB in microglial function in the neuroimmune system.

\section{Introduction}

The tropomyosin-related kinase B receptor (TrkB), part of the Trk family of neurotrophin receptors, plays a crucial role in the maintenance of the adult nervous system. Upon binding to ligands NT-3, NT-4/5, and brain-derived neurotrophic factor (BDNF), monomeric TrkB receptors dimerize, autophosphorylate, and activate signaling pathways to trigger experiencedependent plasticity (for review, see Chao, 2003). Specifically, TrkB activation increases synaptic protein expression, induces long-term potentiation (LTP), modulates dendritic arborization and spine morphology, and increases synaptic strength (Kang and Schuman, 1995; Levine et al., 1996; Scharfman, 1997; Mar-

Received Feb. 20, 2009; revised Feb. 19, 2011; accepted March 17, 2011.

Author contributions: J.L.S.S., E.M.W., K.G.B., B.S.M., and T.A.M. designed research; J.L.S.S., E.M.W., K.G.B., and T.A.M. performed research; E.M.W., K.G.B., M.V.C., B.S.M., and T.A.M. contributed unpublished reagents/analytic tools; J.L.S.S., E.M.W., and T.A.M. analyzed data; J.L.S.S., E.M.W., and T.A.M. wrote the paper.

This work was supported by National Institutes of Health Grants NSO7080 (to B.S.M.), HL18974 and DA08259 (to

T.A.M.), GM07739 and MH082528 (to J.L.S.), and DK07313 (to E.M.W.). We thank Katharine Mitterling and Louisa Thompson for excellent technical assistance.

Correspondence should be addressed to Joanna L. Spencer-Segal, Laboratory of Neuroendocrinology, Box 165, The Rockefeller University, 1230 York Avenue, New York, NY 10065. E-mail: joannalspencer@gmail.com.

DOI:10.1523/JNEUROSCI.0910-11.2011

Copyright $\odot 2011$ the authors $\quad 0270-6474 / 11 / 316780-11 \$ 15.00 / 0$ tínez et al., 1998; Minichiello et al., 1999; Thakker-Varia et al., 2001; Tyler and Pozzo-Miller, 2001; Horch and Katz, 2002; Messaoudi et al., 2002; Miyamoto et al., 2006; Jia et al., 2008; Luikart et al., 2008). These effects underlie the importance of TrkB signaling in hippocampal-dependent learning, memory, and emotional behavior (Minichiello et al., 1999; Mizuno et al., 2003a,b; Monteggia et al., 2004; Chan et al., 2006; Gruart et al., 2007; Heldt et al., 2007; Chen et al., 2010).

Despite the utility of neuronal cell culture, hippocampal slice culture, and transgenic mouse models in studying the functions of TrkB, the precise sites of TrkB activation in the intact organism are still unknown. BDNF and TrkB are widely expressed in the adult hippocampal formation (Conner et al., 1997; Yan et al., 1997; Drake et al., 1999). Identification of the cell types and subcellular locations of TrkB activation under different conditions will provide crucial information about experience-dependent plasticity in vivo.

Hippocampal synaptic plasticity is enhanced by factors that increase BDNF expression, including the ovarian hormone estradiol. During the proestrus stage of the rodent estrous cycle, when circulating estradiol increases, BDNF expression and TrkB activation in the hippocampus also increase (Scharfman et al., 2003, 
2007; Spencer et al., 2008a,b, 2010). Consistent with this phenomenon, estradiol enhances LTP and hippocampal-dependent learning and memory (Warren et al., 1995; Good et al., 1999; Korol et al., 2004; Li et al., 2004; Sandstrom and Williams, 2004; Spencer et al., 2008b). BDNF induction is necessary for estradiol to increase hippocampal excitability and synaptic protein expression, and therefore it may underlie estradiol's ability to enhance hippocampal synaptic plasticity (Scharfman et al., 2003; Scharfman and Maclusky, 2005, 2006; Sato et al., 2007; Spencer et al., 2008b).

To locate the sites of TrkB activation in vivo, we conducted immunocytochemistry using an antibody raised against a phospho-residue (tyrosine 816) in the active TrkB receptor (pTrkB). We performed a quantitative analysis of the sites of pTrkB-immunoreactivity (pTrkB-ir) in the mouse hippocampal formation using electron microscopy. The use of fixed tissue sections ensured identification of the natural sites of TrkB activation, and electron microscopy enabled the most precise localization of $\mathrm{pTrkB}$ labeling. To assess changes in the distribution of pTrkB under conditions of enhanced BDNF-dependent plasticity, we considered hormonal status (estrous cycle stage) as a noninvasive manipulation that influences BDNF expression and hippocampal synaptic plasticity. The distribution of pTrkB-ir was compared between sexes and in different phases of the estrous cycle.

\section{Materials and Methods}

Animals. All experiments were approved by the Weill Cornell Medical College and Rockefeller University Institutional Animal Care and Use Committees and conducted in accordance with the NIH Guide for the Care and Use of Laboratory Animals. Young adult female $(N=18)$ and male $(N=6)$ C57BL/6 wild-type mice (Jackson Laboratory) and c-fmsenhanced green fluorescence protein (EGFP) mice (Sierra et al., 2008) were kept on a 12:12 light/dark cycle (lights on 6:00 A.M.). For the females, estrous cycle stage was determined daily for 2 weeks using vaginal smear cytology (Turner and Bagnara, 1971). Females were perfused in proestrus $(N=6)$, estrus $(N=6)$, or diestrus $(N=6)$ at $10-12$ weeks of age between 9:00 and 11:00 A.M.

Mice were deeply anesthetized with sodium pentobarbital $(150 \mathrm{mg} / \mathrm{kg}$ intraperitoneal) and perfused through the ascending aorta with saline/heparin followed by $40 \mathrm{ml}$ of $3.75 \%$ acrolein, $2 \%$ paraformaldehyde in $0.1 \mathrm{M}$ phosphate buffer $(\mathrm{PB}), \mathrm{pH}$ 7.4. Brains were removed from the skull and postfixed for $30 \mathrm{~min}$ in $2 \%$ acrolein and $2 \%$ paraformaldehyde solution in PB. Coronal sections ( $40 \mu \mathrm{m}$ thick) through the dorsal hippocampal formation were cut on a vibrating microtome (Leica Microsystems) and stored in $30 \%$ ethylene glycol and $30 \%$ sucrose in $\mathrm{PB}$ at $-20^{\circ} \mathrm{C}$.

Female wild-type Sprague Dawley rats (Charles River) were perfused with acrolein/paraformaldehyde solution and hippocampal tissue sections prepared as previously described (Milner et al., 2001).

Antibodies. pTrkB labeling was performed using a rabbit polyclonal antibody that selectively recognizes the activated form of the TrkB receptor (Bath et al., 2008). This antibody was generated using a synthetic peptide (LQNLAKASPVPYLDIC) containing phosphorylated tyrosine 816 of rat TrkB, previously shown to be the site for phospholipase C- $\gamma$ recruitment in response to BDNF (Minichiello, 2009). The generation and characterization of this antibody has been previously described (Bath et al., 2008). Western blot analysis of the affinity-purified antibody showed that it specifically recognizes the activated full-length TrkB in 293 cells stably overexpressing TrkB receptors and in cultured hippocampal neurons (Bath et al., 2008). The antibody does not recognize the truncated TrkB isoform that may have distinct biological effects (Alderson et al., 2000; Rose et al., 2003; Ohira et al., 2005, 2007; Carim-Todd et al., 2009). The antibody also does not recognize activated TrkA receptors in PC12 cells or other tyrosine phosphorylated proteins (Bath et al., 2008). Specificity of this antibody has been verified in preadsorption controls performed on fixed tissue sections from the olfactory bulb and Western blot (Bath et al., 2008). Moreover, in aldehyde-fixed olfactory bulb tissue and brains of $\operatorname{TrkB}$ receptor haploinsufficient $\left(\operatorname{TrkB}^{+/-}\right)$mice, $\mathrm{pTrkB}-$ immunoreactivity is markedly decreased (Bath et al., 2008).
In the present study, specificity of the pTrkB antibody was determined two additional ways. First, acrolein-fixed hippocampal sections were incubated in pTrkB antibody that had been preadsorbed with the peptide against which the antibody was raised and processed for light and electron microscopic immunocytochemistry as described above. Second, paraformaldehyde-fixed coronal sections through the hippocampus from 1-d-old TrkB ${ }^{+/-}$and $\mathrm{TrkB}^{-/-}$mice were processed for light microscopic peroxidase immunocytochemistry as described above. Although all precautions were taken to ensure that the antibody specifically recognized $\mathrm{p}$ TrkB, it is possible that it could recognize peptide sequences contained in other proteins, such as TrkC receptors. Thus, the labeling described in the present study should be interpreted as pTrkB-like immunoreactivity.

Dynorphin labeling was performed using a guinea pig polyclonal antidynorphin from Bachem. Specificity of this antibody has previously been verified (Svingos et al., 1999). Glial fibrillary acidic protein (GFAP) labeling was performed using a mouse polyclonal anti-GFAP from Millipore. EGFP labeling was performed using a chicken polyclonal anti-GFP antibody (Aves Labs). OX-42 labeling was performed using a mouse monoclonal anti-OX-42 antibody (Serotec).

Immunocytochemistry. To determine the distribution of pTrkB-ir in the dorsal hippocampal formation, immunocytochemical localization was performed on two sections per mouse using the avidin biotin complex (ABC) protocol (Hsu and Raine, 1981). Briefly, sections were washed in PB followed by $1 \%$ sodium borohydride in PB (30 min), blocked in $0.5 \%$ bovine serum albumin (BSA) in $0.9 \%$ saline in $0.1 \mathrm{M}$ Tris, pH 7.6 (TS), and incubated in primary antiserum (pTrkB, 1:1000) in $0.1 \%$ BSA in TS for $3 \mathrm{~d}$ at room temperature. Antiserum for control sections was preabsorbed with excess pTrkB-blocking peptide. Sections were incubated in secondary antiserum and biotylinated goat anti-rabbit IgG in TS (1:400; Vector Laboratories) for $30 \mathrm{~min}$. Sections then were labeled with $\mathrm{ABC}$ using the Vectastain Elite kit (Vecor Laboratories). Labeling was visualized with $3,3^{\prime}$-diaminobenzidine (Sigma-Aldrich) and hydrogen peroxide in TS. Labeled sections were mounted on slides, dehydrated in an alcohol series, and coverslipped.

To verify the localization and more discretely visualize the pTrkB immunoreactivity, a few sections were labeled using gold particles conjugated to secondary antibody (Chan et al., 1990). Instead of the secondary antisera described above, these sections were incubated in colloidal goldlabeled (1 nM) goat anti-rabbit IgG (1:50; Electron Microscopy Sciences) in $0.08 \%$ BSA, $0.01 \%$ gelatin in PB with $0.9 \%$ saline (PBS) for $2 \mathrm{~h}$ at room temperature. These sections were postfixed in $2 \%$ glutaraldehyde in PBS for $10 \mathrm{~min}$ followed by $0.2 \mathrm{M}$ sodium citrate buffer, $\mathrm{pH}$ 7.4. Gold labeling was enhanced using a silver solution (IntenSE; GE Healthcare).

To determine whether pTrkB labeled mossy fiber axon bundles and terminals in CA3, a few sections were double-labeled for pTrkB and dynorphin, an opioid peptide contained exclusively in mossy fiber axons and terminals in the CA3 (Drake et al., 2007). First, tissue was labeled with pTrkB primary antiserum (1:2000) as described above. Tissue was then incubated in dynorphin primary antiserum (1:2000) with $0.025 \%$ Triton for $48 \mathrm{~h}$ at $4^{\circ} \mathrm{C}$. pTrkB labeling was then completed using the $\mathrm{ABC}$ protocol as described above. Dynorphin labeling was completed using colloidal gold-labeled anti-guinea pig IgG (1:50) for the secondary antiserum as described above for pTrkB (Chan et al., 1990).

Sections for electron microscopy were incubated in $2 \%$ osmium tetroxide $(1 \mathrm{~h})$ and dehydrated in an alcohol series and propylene oxide. They then were embedded in EMBed 812 (Electron Microscopy Sciences) between two sheets of plastic (Chan et al., 1990). One embedded section from three animals in each group (proestrus, estrus, diestrus, and male) was selected and mounted on Epon chucks (total $N=12$ ). Ultrathin $70 \mathrm{~nm}$ sections within $1.5 \mathrm{~mm}$ of the tissue surface were cut on a Leica UTC Ultratome (Leica Microsystems), collected on grids, and counterstained with uranyl acetate and Reynold's lead citrate. Sections were examined on a Tecnai Biotwin transmission electron microscope (FEI) and images acquired using Advanced Microscopy Techniques software (v. 3.2). Digital images for figures were cropped and adjusted for levels, brightness, contrast, and sharpness in Adobe Photoshop 7.0, and final figures were assembled in Adobe Photoshop (v 9.0.2) and Microsoft Powerpoint $\mathrm{X}$ for Mac. 
To further investigate the pTrkB labeling in glia, double-label immunofluorescence was performed on sections from female wild-type mice or c-fms-EGFP mice [in which the brain microglia express the EGFP protein under control of the macrophage colony-stimulating factor promoter (Sierra et al., 2008)] and wildtype rats. Sections were prepared as above through the blocking step. They were incubated in $\mathrm{pTrkB}$ primary antiserum $(1: 100)$ for $48 \mathrm{~h}$ at room temperature. GFAP (1:5000), OX-42 (1:1000), or GFP (1:5000) antiserum was then added for an additional $48 \mathrm{~h}$ at $4^{\circ} \mathrm{C}$. On the final day, tissue was washed with TS and incubated sequentially in the appropriate fluorophore-conjugated secondary antibodies ( $1: 400)$, each for $1 \mathrm{~h}$ at room temperature. Secondary antibodies included Cy2-conjugated anti-rabbit, Cy2-conjugated anti-chicken, Cy5-conjugated anti-mouse, and Cy5conjugated anti-rabbit (Jackson Immunoresearch Laboratories). After final washes in TS, the tissue was mounted, dried, dehydrated in an alcohol series, and coverslipped using Krystalon mounting medium (Harleco; EM Diagnostics).

Quantitative analysis. Three animals from each group (males and proestrus, diestrus, and estrus females) were used for the quantitative analysis. One block from each hippocampal region (CA1, CA3, and dentate gyrus) was analyzed per animal. From each of the following hippocampal laminae, $220.5 \mu \mathrm{m}^{2}$ of neuropil were examined: stratum oriens, stratum radiatum (proximal to the pyramidal cell layer), stratum radiatum (distal to the pyramidal cell layer), and lacunosum moleculare of CA1; stratum oriens, stratum lucidum, and stratum radiatum of CA3; and outer, middle, and inner thirds of the molecular layer, subgranular zone, and central hilus of the dentate gyrus. Laminae containing principal cell perikarya were excluded from this analysis because the large size of the cell bodies and nuclei makes it difficult to accurately quantify this labeling using random field sampling. The distribution of pTrkB labeling was determined by counting immunolabeled profiles, which were classified using accepted nomenclature (Peters et al., 1991). Dendrites contained microtubular arrays and synaptic contacts with adjacent axon terminals. Spines had a smaller diameter than dendrites (usually $<0.2$ $\mu \mathrm{m})$ and contacted neighboring axon terminals. Unmyelinated axons had a small diameter $(<0.2 \mu \mathrm{m})$, few vesicles, and no synaptic contacts in the plane of section. Axon terminals had a larger diameter than axons, contained numerous vesicles, and made synaptic contacts with neighboring dendritic spines or shafts. Glial profiles contained no microtubules and conformed to the shape of surrounding structures. In addition to this identification of labeled profiles, all unlabeled axon terminals and dendritic spines were counted in the distal CA1 stratum radiatum to determine the percentage of axon terminals and dendritic spines containing pTrkB-ir.

Fluorescence microscopy. Immunofluorescence images were acquired sequentially using a confocal laser-scanning microscope (Leica). Z-stack analysis was used to verify whether neurons were dually labeled for pTrkB and GFAP, TrkB, c-fms, or OX-42.

Statistical analysis. For each animal, the number of labeled profiles in each cell compartment within one lamina was expressed as a percentage of the total counted profiles in the whole hippocampal formation. Means for each estrous cycle group and males were compared using two-way ANOVA and Bonferroni post hoc tests in Prism 5.0 software. The number of labeled axon terminals and dendritic spines in distal CA1 stratum radiatum was expressed as a percentage of the total terminals or spines in this lamina.

\section{Results}

Light microscopic immunolocalization of $p \operatorname{TrkB}$ in the hippocampal formation

We previously described the light microscopic immunolocalization of TrkB phosphorylated at tyrosine 816 (pTrkB) in the
Table 1. pTrkB-labeled profiles in individual hippocampal laminae

\begin{tabular}{rlrlllr}
\hline Subregion & Lamina & Dendrites & Spines & Terminals & Axons & Glia \\
\hline CA1 & S0 & 6 & 4 & 6 & 20 & 8 \\
& SR proximal & 6 & 1 & 5 & 15 & 11 \\
& SR distal & 10 & 4 & 8 & 6 & 10 \\
\multirow{4}{*}{ CA3 } & SLM & 5 & 1 & 0 & 10 & 12 \\
& SO & 3 & 1 & 3 & 17 & 5 \\
& SR & 5 & 1 & 10 & 5 & 1 \\
\multirow{5}{*}{ DG } & SL & 2 & 2 & 6 & 8 & 5 \\
& OML & 7 & 1 & 4 & 7 & 6 \\
& MML & 7 & 1 & 4 & 3 & 5 \\
& IML & 4 & 1 & 3 & 6 & 5 \\
& SGZ & 1 & 2 & 1 & 11 & 12 \\
& HIL & 6 & 5 & 6 & 8 & 12 \\
\hline
\end{tabular}

Number of profiles counted from one representative female mouse in diestrus. SO, Stratum oriens; SR, stratum radiatum; $\mathrm{SLM}$, stratum lacunosum moleculare; $\mathrm{SL}$, stratum lucidum; $\mathrm{DG}$, dentate gyrus; $\mathrm{OML}$, outer molecular layer MML, middle molecular layer; IML, inner molecular layer; $S G Z$, subgranular zone; HIL, hilus.

hippocampal formation of female mice perfused with $4 \%$ paraformaldehyde (Spencer et al., 2008a). In that study, we used a well characterized antibody raised against a C-terminal phospholipaseC-gamma phosphorylation site on the full-length TrkB (Bath et al., 2008). To determine whether this antibody elicits a similar labeling pattern in mice prepared for electron microscopy, we localized pTrkB-ir using light microscopy in female mice perfused with acrolein and paraformaldehyde. pTrkB-ir localized to CA1, CA3, and the dentate gyrus of the dorsal hippocampal formation (Fig. $1 A, C$ ). The labeling pattern was consistent with the previously described pattern, showing pTrkB labeling in both cell bodies and neuropil, representing neuronal and/or glial processes. Preadsorption of the primary antisera with $\mathrm{pTrkB}$ blocking peptide eliminated all labeling (Fig. $1 B$ ).

To further demonstrate the specificity of the pTrkB antibody in mouse hippocampus, paraformaldehyde-fixed hippocampal sections from postnatal 1-d-old TrkB haploinsufficient $\left(\right.$ TrkB $\left.^{+/-}\right)$mice (Fig. $\left.1 D\right)$ and TrkB deficient $\left(\operatorname{TrkB}^{-/-}\right)$mice were incubated in the antibody and processed for immunoperoxidase labeling. Immunoreactivity in all regions of the hippocampus was visible in $\operatorname{TrkB}^{+/-}$mice (Fig. $1 D$ ) and virtually undetectable in TrkB ${ }^{-1-}$ mice (Fig. $1 E$ ).

\section{Electron microscopic immunolocalization of pTrkB in the hippocampal formation}

To determine the distribution of pTrkB in neurons and glia, pTrkB-ir was identified using electron microscopy in the dor- 
Table 2. Distribution of $p$ TrkB-IR in the hippocampal formation of female cycling and male mice

\begin{tabular}{|c|c|c|c|c|c|c|c|}
\hline Subregion & Cycle/sex & \% Dendrites & Spines & Terminals & Axons & Glia & Total \\
\hline \multirow[t]{4}{*}{ CA1 } & Proestrus & $6.1 \pm 1.0$ & $3.6 \pm 0.8$ & $9.2 \pm 0.5$ & $16.1^{*} \pm 0.7$ & $9.9 \pm 0.3$ & $44.9 \pm 2.1$ \\
\hline & Estrus & $8.0 \pm 1.2$ & $5.2 \pm 0.8$ & $7.9 \pm 2.4$ & $11.8 \pm 1.9$ & $5.7 \pm 0.3$ & $38.7 \pm 2.4$ \\
\hline & Diestrus & $6.5 \pm 0.6$ & $3.4 \pm 1.2$ & $6.0 \pm 1.7$ & $13.8 \pm 2.3$ & $8.6 \pm 1.6$ & $38.3 \pm 3.4$ \\
\hline & Male & $7.3 \pm 0.01$ & $3.4 \pm 0.8$ & $6.0 \pm 0.6$ & $10.9 \pm 0.8$ & $6.0 \pm 0.6$ & $33.5 \pm 1.3$ \\
\hline \multirow[t]{4}{*}{ CA3 } & Proestrus & $2.5 \pm 0.6$ & $2.6 \pm 0.8$ & $3.6 \pm 0.08$ & $8.9 \pm 0.9$ & $3.1 \pm 0.3$ & $20.7 \pm 2.0$ \\
\hline & Estrus & $3.0 \pm 0.7$ & $4.3 \pm 0.5$ & $5.4 \pm 0.3$ & $7.5 \pm 0.9$ & $4.2 \pm 0.04$ & $24.3 \pm 2.5$ \\
\hline & Diestrus & $2.6 \pm 0.1$ & $3.7 \pm 1.5$ & $5.0 \pm 1.0$ & $9.4 \pm 1.1$ & $3.3 \pm 0.9$ & $24.1 \pm 1.7$ \\
\hline & Male & $4.3 \pm 0.3$ & $3.1 \pm 0.1$ & $6.4 \pm 1.0$ & $6.7 \pm 0.7$ & $3.3 \pm 0.4$ & $23.8 \pm 0.4$ \\
\hline \multirow[t]{4}{*}{ DG } & Proestrus & $5.2 \pm 0.5$ & $2.4 \pm 0.7$ & $5.2 \pm 0.6$ & $14.0 \pm 3.0$ & $7.6 \pm 0.72$ & $34.4 \pm 1.5$ \\
\hline & Estrus & $6.6 \pm 0.8$ & $4.4 \pm 0.5$ & $4.5 \pm 0.8$ & $13.8 \pm 1.6$ & $7.6 \pm 1.5$ & $37.0 \pm 2.2$ \\
\hline & Diestrus & $6.8 \pm 0.4$ & $3.1 \pm 0.5$ & $5.0 \pm 1.0$ & $14.1 \pm 2.2$ & $8.6 \pm 1.8$ & $37.6 \pm 3.7$ \\
\hline & Male & $7.9 \pm 0.6$ & $3.6 \pm 0.7$ & $5.0 \pm 1.0$ & $16.8 \pm 0.7$ & $9.2 \pm 1.7$ & $42.6 \pm 1.0$ \\
\hline Total & & $16.7 \pm 0.9$ & $10.7 \pm 0.7$ & $17.3 \pm 0.6$ & $36.0 \pm 1.3$ & $19.3 \pm 0.9$ & \\
\hline
\end{tabular}

A total area of $2646 \mu \mathrm{m}^{2}$ was analyzed per animal $(N=3)$. Numbers represent the percentage of all counted profiles in the hippocampal formation, \pm SEM. Boldface indicates a significant effect of cycle/sex, $p<0.05$. ${ }^{*} p<0.05$ relative to male mice by post hoc test. DG, Dentate gyrus.

sal hippocampal formation of nine female (three per estrous cycle stage) and three male mice. Consistent with the light microscopic labeling pattern, pTrkB labeling was seen throughout the hippocampal formation in laminae containing principal cell perikarya and neuropil. The light microscopic immunolocalization (Fig. $1 A, C$ ) suggested a greater density of pTrkB labeling in principal cell perikarya relative to the neuropil. It was not possible to quantify the principal cell pTrkB labeling in the electron micrographs by the random sampling method used in this study. Based on our observations, the relative darkness of the principal cell perikarya on the light micrographs does not translate to a relative abundance of pTrkB labeling in the soma by electron microscopy. This discrepancy between pTrkB labeling patterns on light and electron microscopy likely reflects the greater depth of focus and limited resolution of light microscopy, as previously described (Milner et al., 1998).

\section{Presynaptic profiles contain the most pTrkB-ir}

Profiles were counted from 12 different hippocampal laminae lacking principal cell perikarya in CA1, CA3, and dentate, for a total area of $2646 \mu \mathrm{m}^{2}$ per mouse. An average of $388.3 \pm 19.03$ labeled profiles were counted for each animal, with no difference between estrous cycle stages or sexes. Table 1 shows the number of pTrkB-labeled profiles of each type in each of the 12 hippocampal laminae from one representative diestrus female. Labeled profiles were identified as dendrites, dendritic spines, axons, axon terminals, glia, or perikarya. Less than $1 \%$ of labeled profiles were unidentifiable or perikarya, and these were excluded from the analyses.

Table 2 shows the distribution of pTrkB-ir in the entire hippocampal formation as a percentage of the total number of counted labeled profiles, averaged for all 12 animals and broken down by estrous cycle stage and sex. The majority of pTrkB-ir was found in presynaptic profiles regardless of sex or estrous cycle stage, with $36.0 \pm 1.3 \%$ in axons and $17.3 \pm 0.6 \%$ in axon terminals. Postsynaptic profiles contained one-quarter of the pTrkB-ir, with $16.7 \pm 0.9 \%$ in dendrites and $10.7 \pm 0.7 \%$ in dendritic spines. Glial profiles accounted for one-fifth of the total pTrkB-ir, $19.3 \pm 0.9 \%$.

\section{Axons and axon terminals, including mossy fibers, contain pTrkB-ir}

Throughout the hippocampal formation, pTrkb-ir was affiliated with the plasma membrane of small unmyelinated axons (Fig. 2). Occasionally, larger myelinated axons contained pTrkB-ir, usu-

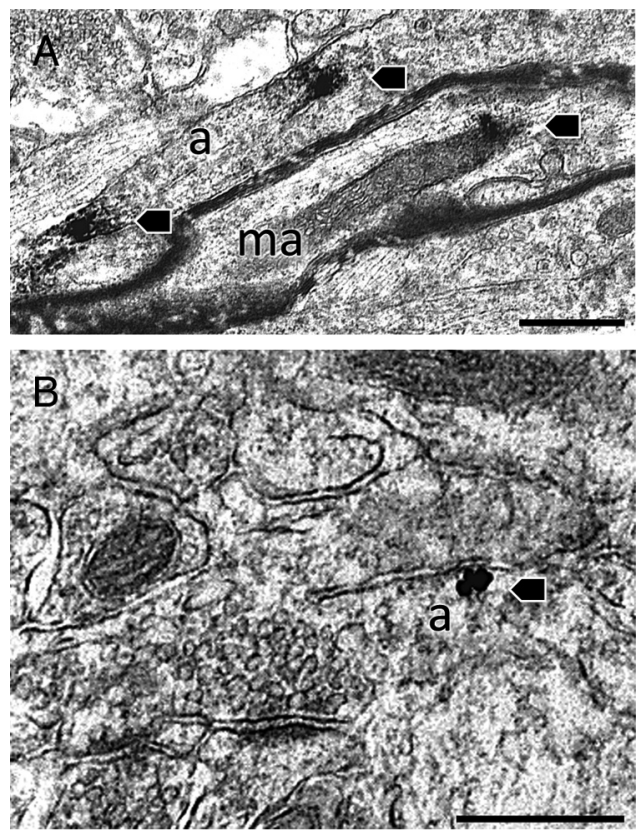

Figure 2. By electron microscopy, pTrkB-ir is most prominent in axons throughout the hippocampal formation. $\boldsymbol{A}$, In the stratum lucidum, pTrkB-ir (arrowheads) is found in axon bundles (a) most likely belonging to the mossy fiber pathway, and in myelinated axons (ma). $\boldsymbol{B}$, In CA1 stratum radiatum, SIG pTrkB-ir (arrowhead) is found in axons near the plasma membrane. Scale bars, $0.5 \mu \mathrm{m}$.

ally affiliated with endomembranes or mitochondria (Fig. 2A). Diffuse pTrkB-ir filled the cytoplasm of some small-caliber axons (Fig. 2A). pTrkB-ir also was localized using silver-intensified gold particles (SIG), allowing more discrete localization of labeling. In axons, pTrkB SIG-immunoreactivity was seen both in the cytoplasm and on or near the plasma membrane (Fig. $2 B$ ).

In terminals, the pTrkB-ir was in clusters most often affiliated with small synaptic vesicles opposite the synaptic contact (Fig. $3 A$ ). SIG labeling confirmed the localization of pTrkB-ir in axon terminals and further revealed pTrkB-ir adjacent to the presynaptic contact, or on mitochondria inside the axon terminal (Fig. $3 B$ ). pTrkB-ir was rarely found in axon terminals making symmetric synapses; as a result, axon terminals forming both types of synapses were pooled for quantitative analyses.

Discrete patches of p TrkB-ir localized to small synaptic vesicles of large terminals with morphological characteristics of mossy fibers in the CA3 stratum lucidum (Fig. 3C). These terminals often contained 
several patches of immunolabeling. Occasionally, labeled terminals contacted pTrkB-labeled spines (Fig. 3C). To confirm the localization of pTrkB-ir to mossy fibers and terminals, we dually labeled a few sections for pTrkB and the opioid peptide dynorphin, which is exclusively found in mossy fibers in the stratum lucidum (Drake et al., 2007). Indeed, dynorphinimmunoreactive axon bundles and mossy fiber terminals contained pTrkB-ir (Fig. $3 D$ ), confirming that pTrkB-ir localizes to the mossy fiber pathway in the mouse.

\section{Dendrites and dendritic spines contain pTrkB-ir}

In dendrites, both $\mathrm{ABC}$-peroxidase and SIG labeling showed pTrkB-ir affiliated with the plasma membrane and endomembranes (Fig. 4). A single dendrite often contained several patches of pTrkB-ir. In contrast to the pTrkB-ir contained in axon terminals, which was usually affiliated with vesicles opposite the synaptic contact, pTrkB-ir in dendritic spines was often adjacent to the synaptic contact (Fig. 5A,B). Occasionally, a labeled dendritic spine was contacted by a labeled axon terminal (Fig. 5A). In stratum lucidum of CA3, pTrkB-ir was found in dendritic spines contacted by mossy fiber terminals (Fig. 5C).

Few synaptic contacts contain pTrkB-ir To determine the proportion of synaptic contacts containing pTrkB labeling, labeled and unlabeled axon terminals and dendritic spines in the distal CA1 stratum radiatum were counted. In this lamina, axon terminals were present at a density of 0.59 per $\mu \mathrm{m}^{2}$, and dendritic spines at 0.47 per $\mu \mathrm{m}^{2}$. The greater density of terminals reflects the presence of some axon terminals making asymmetric contacts with dendritic shafts, and the relative ease of identifying terminals outside the plane of the synaptic contact. pTrkB immunoreactivity was discerned in only $6.1 \pm 0.7 \%$ of axon terminals and $4.7 \pm 0.8 \%$ of dendritic spines. Student's $t$ test showed no significant difference between the percentage of labeled spines and terminals $[(t, \mathrm{df})=1.364,22, p=0.1864 ; N=12]$. This suggests that at a given time, TrkB is activated in a similar and very small proportion of the total axon terminals and dendritic spines in the distal CA1 stratum radiatum of the mouse.
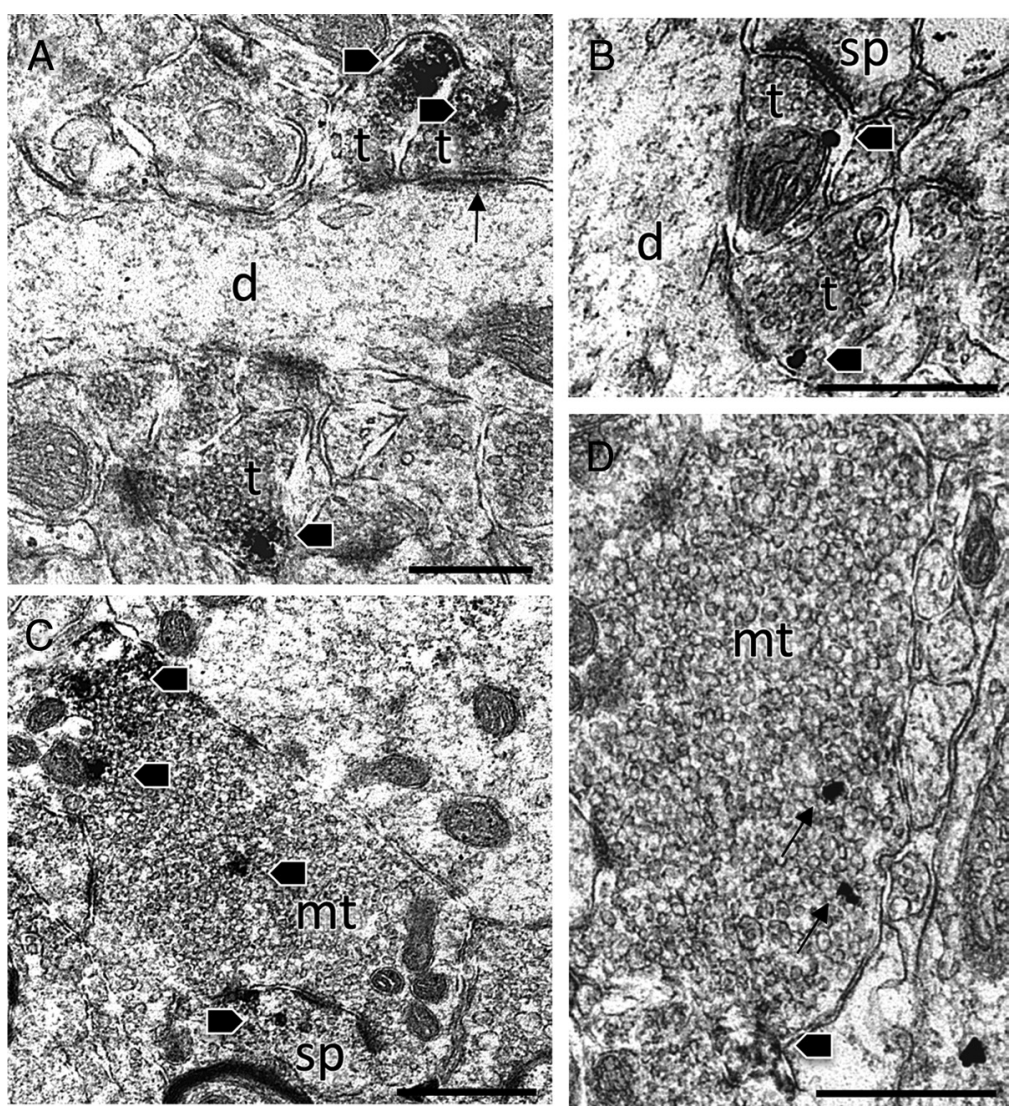

Figure 3. pTrkB-ir is found in axon terminals throughout the hippocampal formation. $A$, In the CA1 stratum radiatum, pTrkB-ir (arrowheads) clusters among small synaptic vesicles in axon terminals ( $t$ ). One of the pTrkB-labeled terminals forms an asymmetric synapse (arrow) with the shaft of an unlabeled dendrite (d). B, In the CA1 stratum radiatum, SIG pTrkB-ir (arrowheads) is in axon terminals, on the membrane of a mitochondrion, and affiliated with small synaptic vesides adjacent to the synaptic contact. $C$, A mossy fiber terminal ( $\mathrm{mt}$ ) in the CA3 stratum lucidum contains pTrkB-ir (arrowheads) associated with small synaptic vesicles and mitochondria. The pTrkB-labeled mossy fiber terminal contacts a dendritic spine (sp) also containing pTrkB-ir (arrowhead). D, A large mossy fiber terminal with dynorphin-ir (SIG, arrows) shows clusters of pTrkB-ir (arrowheads) associated with vesicles near the plasma membrane. Scale bars, $0.5 \mu \mathrm{m}$.


Figure 4. $\quad$ TrkB-ir is found in dendritic shafts throughout the hippocampal formation. $\boldsymbol{A}$, In the CA1 stratum radiatum, clusters of pTrkB-ir (arrowheads) are found near the plasma membrane in dendritic shafts (d). $\boldsymbol{B}$, Immunogold labeling for pTrkB (arrowheads) is on the plasma membrane within the dendrite. Scale bars, $0.5 \mu \mathrm{m}$.

\section{Glial profiles contain pTrkB-ir}

The role of TrkB in glial cell function in the adult has received very little attention. It is widely believed that glia express only the truncated TrkB isoform lacking the intracellular catalytic domain
(Alderson et al., 2000; Rose et al., 2003; Ohira et al., 2005, 2007), though cortical glia in culture were found to express a small amount of functional full-length TrkB (Roback et al., 1995). Therefore, it was surprising that approximately one-fifth of the 

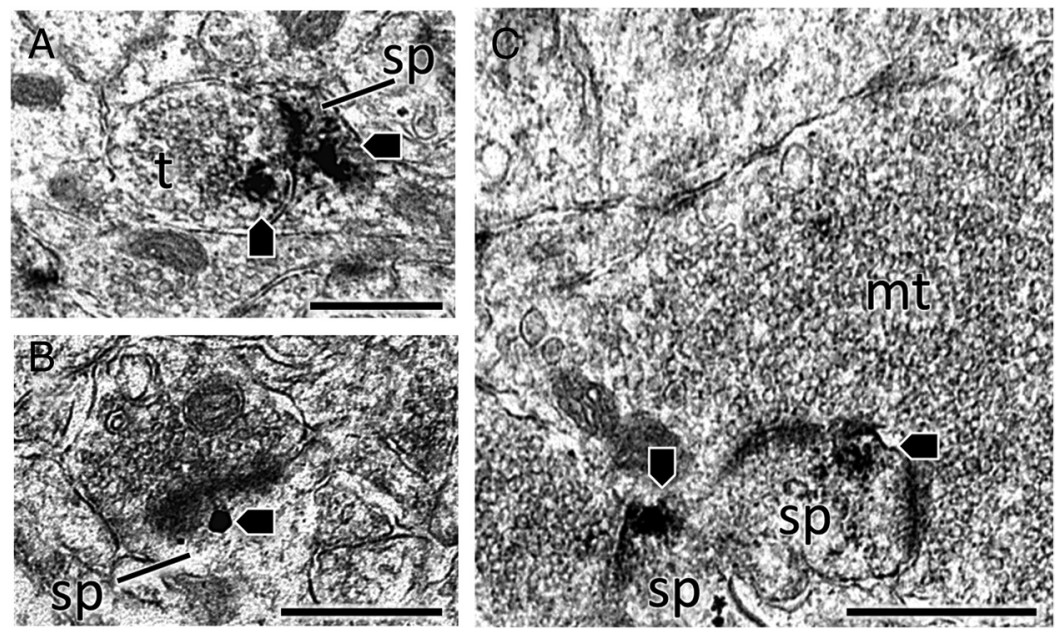

Figure 5. pTrkB-ir is found in dendritic spines throughout the hippocampal formation. $\boldsymbol{A}$, In the CA1 stratum radiatum, a dendritic spine (sp) containing pTrkB-ir (arrowheads) is contacted by a labeled axon terminal (t). $\boldsymbol{B}$, SIG labeling shows pTrkB-ir (arrowhead) clustered next to the postsynaptic density in a dendritic spine. $C$, In the CA3 stratum lucidum, an unlabeled mossy fiber terminal (mt) contacts two separate spines containing pTrkB-ir (arrowheads). Scale bars, $0.5 \mu \mathrm{m}$. sections from female mice with the $\mathrm{p} \operatorname{TrkB}$ antibody and an antibody against GFAP, which specifically labels fibrous astrocytes (Fig. 7A-C). We found no colocalization between the pTrkB and GFAP labeling, suggesting that the $\mathrm{pTrkB}$ immunoreactivity is not found in fibrous astrocytes.

Instead of astrocytes, the glial pTrkB-ir may represent $p$ TrkB labeling in other types of glial cells, such as microglia. Although TrkB expression in microglia in vivo has not previously been reported, several microglial cell lines in vitro express Trk receptors and proliferate in response to their stimulation (Zhang et al., 2003). To determine whether the pTrkB antibody labels microglia, we first used sections through the dorsal hippocampus of c-fms-EGFP mice, in which brain microglia express the EGFP protein under control of the macrophage colonystimulating factor promoter (Sierra et al., 2008). Sections through the dorsal hip-
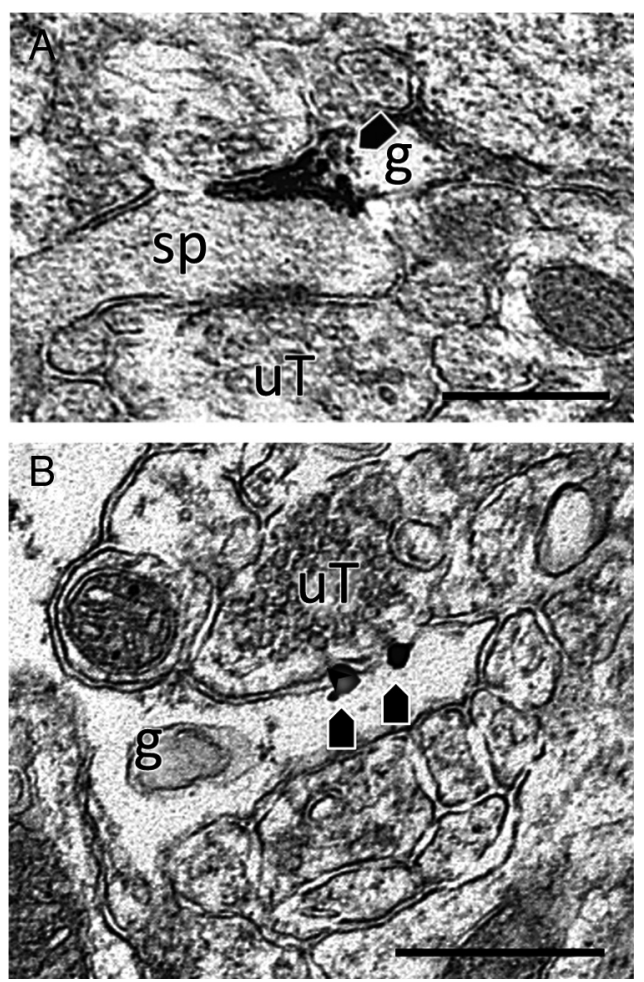

Figure 6. $\mathrm{pTrkB}$-ir is found in glial profiles throughout the hippocampal formation. $A$, In the CA1 stratum radiatum, diffuse peroxidase pTrkB-ir (arrowhead) is found in a glial profiles (g). $\boldsymbol{B}$, SIG pTrkB-ir (arrowheads) is affiliated with the plasma membrane of a glial profile. sp, Dendritic spine; $\mathrm{UT}$, unlabeled terminal. Scale bars, $0.5 \mu \mathrm{m}$.

pTrkB labeling was found in glial profiles. Diffuse pTrkB-ir was seen in glial profiles from sections labeled using the $\mathrm{ABC}$ peroxidase method (Fig. $6 \mathrm{~A}$ ), and SIG pTrkB-ir was primarily on the plasma membrane of glia (Fig. $6 B$ ).

Because the electron microscopy did not allow us to distinguish among different types of glial profiles containing pTrkB, we used immunofluorescence and confocal microscopy to further investigate the glial labeling. To determine whether the pTrkB antibody labels astrocytes, we double-labeled hippocampal pocampus of these mice were labeled with anti-pTrkB and antiGFP antibodies (Fig. $7 D-F$ ). There was extensive colocalization of pTrkB and c-fms in the hippocampal formation of these mice, suggesting that $\mathrm{pTrkB}$ is in microglia. We also labeled sections through the dorsal hippocampus of female rats with the antipTrkB antibody and an antibody against the microglial marker, OX-42, which works well in rat but not mouse tissue (Fig. 7G-I). The labeling for these two proteins also colocalized, demonstrating the presence of pTrkB in microglia in the rat hippocampus. Thus, the pTrkB labeling in glial profiles likely reflects the presence of pTrkB in microglia; this finding is conserved between

\section{Sex and estrous cycle affect the distribution of pTrkB immunoreactivity}

By light microscopy, pTrkB-ir increases in the mouse hippocampal formation during proestrus, suggesting that increased TrkB phosphorylation and activity may be responsible for the increase in hippocampal excitability seen during this cycle phase (Scharfman et al., 2003; Spencer et al., 2008a,b, 2010). Whether this increase in $\mathrm{pTrkB}$-ir involves a global increase in $\mathrm{pTrkB}$ or a more selective increase in specific lamina and cell types is unknown. We investigated whether a shift in the distribution of pTrkB-ir accompanies the rise in estradiol during proestrus by comparing the distribution of pTrkB-ir by electron microscopy in proestrus females with its distribution in estrus and diestrus females and in males (Table 2).

During proestrus, there was an increase in the proportion of pTrkB-labeled profiles contained in the CA1 subregion. In proestrus females, $44.9 \%$ of the total pTrkB-labeled profiles were found in the CAl, a higher proportion than in other groups of females or males (Table 2). When analyzed by two-way ANOVA, this was evident statistically as an overall effect of cycle phase on profile percentage in the CA1 region $\left(F_{(3,40)}=3.047, p=0.0396\right)$. The most striking difference was between sexes: proestrus females had 34\% more pTrkB-ir in the CA1 than males. Post hoc tests revealed that proestrus females had significantly more pTrkB-labeled axons in CA1 than males $(p<0.05)$. In contrast, there were no significant changes in the distribution of pTrkB-ir in the $\mathrm{CA} 3$ or dentate gyrus across the estrous cycle or between sexes. mice and rats. 
To determine which laminae and cell types might account for the increase in pTrkB-ir in the CA1 during proestrus, we compared the distribution of pTrkB-ir in each of the four CA1 laminae (Fig. 8). We found that significant shifts in the distribution of pTrkB-ir occurred in CA1 stratum radiatum (Fig. 8B,C). Two-way ANOVA showed a significant effect of estrous cycle phase/sex in both proximal stratum radiatum $\left(F_{(3,40)}=3.243, p=\right.$ $0.0319)$ and distal stratum radiatum $\left(F_{(3,40)}=3.606, p=0.0214\right)$. Post hoc tests showed that proestrus mice had more pTrkB-labeled glia in the proximal stratum radiatum than estrus $(p<0.05)$ and male $(p<0.01)$ mice, whereas proestrus mice had more pTrkB-labeled axons in the distal stratum radiatum than estrus, diestrus, or male mice ( $p<0.01$ for all). Thus, the overall increase in pTrkB-ir in the CA1 during proestrus occurred primarily via an increase in pTrkB-labeled glia and axons in the CA1 stratum radiatum, with the distribution of pTrkB-ir in male mice resembling that of lowestradiol (estrus or diestrus) females.

\section{Discussion}

This study is the first to precisely localize activated $\operatorname{TrkB}$ in the mouse hippocampal formation. Our previous immunocytochemical localization of total TrkB in the rat hippocampal formation using electron microscopy showed abundant labeling of axon initial segments (Drake et al., 1999), suggesting extensive trafficking of TrkB to axons. We also showed previously that increases in hippocampal pTrkB-ir were found during periods of high estrogen levels using light microscopy (Spencer et al., 2008a).

The current study extends these findings, showing that the majority of activated TrkB, measured as pTrkB-ir, is in axons and axon terminals in the mouse hippocampal formation, and that the amount of presynaptic pTrkB fluctuates across the estrous cycle.

\section{pTrkB is positioned to locally regulate synaptic transmission and neurite growth}

In axons, the largely intracellular localization of pTrkB-ir suggests that the rapid endocytosis of activated TrkB described in cultured neurons may also occur in vivo (Du et al., 2003). This internalized $\mathrm{p}$ TrkB would be well positioned for local degradation or recycling back to the plasma membrane (Chen et al., 2005; Zheng et al., 2008). Alternatively, the pTrkB-ir affiliated with small synaptic vesicles distal to the synaptic contact in axon terminals may in fact be in transit down the axon. Such retrograde transport of pTrkB-ligand complexes has been previously described and may function to communicate TrkB signaling from the synapse to the cell body (Bhattacharyya et al., 1997; Watson et al., 1999) in a manner similar to NGF-TrkA signaling (Niewiadomska et al., 2010). The axonal pTrkB-ir seen in affiliation with small membranous structures, termed endomembranes, may represent the signaling endosomes proposed to maintain receptor signaling during retrograde transport (Cosker et al., 2008).

pTrkB-ir was occasionally affiliated with the mitochondrial membrane in axons and axon terminals. Activation of mitochondrial TrkB by G-protein couple receptor (GPCR) signaling increases the number of extracellular stimuli that may generate a cell response (Rajagopal and Chao, 2006). TrkB has previously been localized to the mitochondrial membrane only in skeletal muscle (Wiedemann et al., 2006), and so the presence of pTrkB-ir in hippocampal mitochondria implies a novel role for TrkB signaling in oxidative metabolism in the brain.

In all compartments, pTrkB-ir was found affiliated with the plasma membrane. But in contrast to axons and axon terminals, where pTrkB-ir was largely intracellular, in dendritic spines the majority of pTrkB-ir was affiliated with the plasma membrane. Interestingly, this localization did not fluctuate over the estrous cycle. This suggests that in the dendritic spine, TrkB stays exposed and responsive to released BDNF rather than being internalized and trafficked as found in the axon. Thus, TrkB activity may be managed differently in the presynaptic versus the postsynaptic compartment. The localization of pTrkB-ir to the plasma membrane at asymmetric synapses and neuronal processes in the current study implies that TrkB locally modulates excitatory synaptic function and neurite growth in the intact mouse. This supports the findings of numerous in vitro studies showing that TrkB modulates presynaptic and postsynaptic function at excitatory synapses (Alsina et al., 2001; Horch and Katz, 2002; Horch, 2004; Ji et al., 2005; Gomes et al., 2006; Magby et al., 2006; Rex et al., 2007). In contrast, the relative absence of p TrkB at inhibitory synapses, identified based on their symmetric morphology, sug- 
A

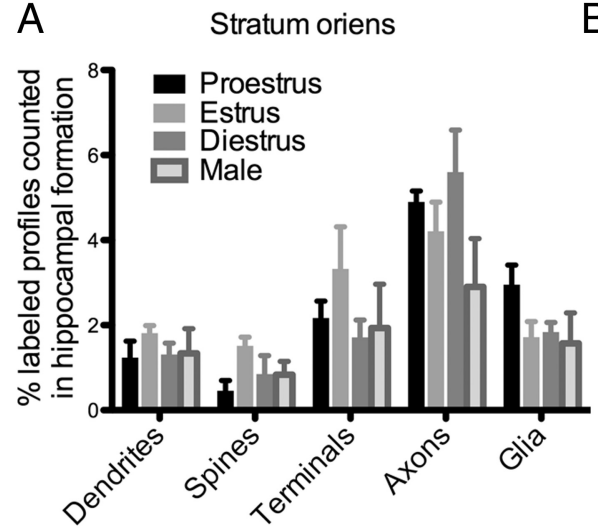

C

Distal stratum radiatum

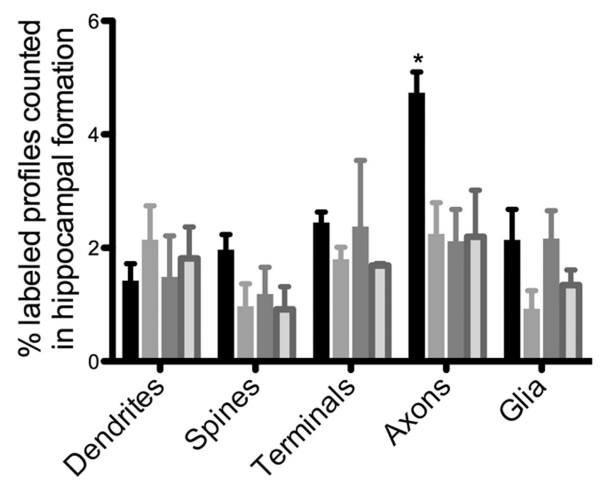

\section{$\mathrm{D}$}

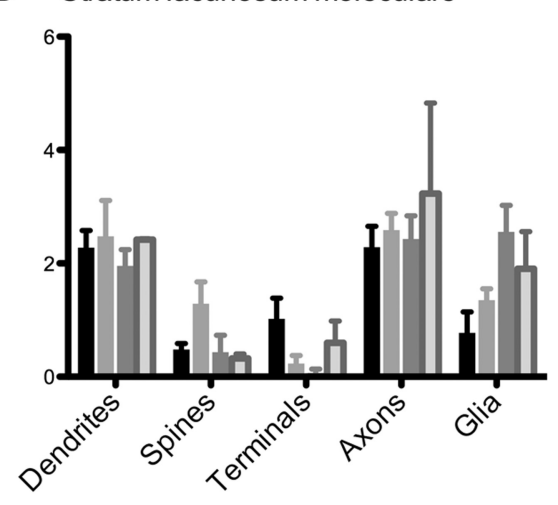

Figure 8. pTrkB-ir in the CA1 stratum radiatum is affected by estrous cycle stage. $A-D$, The number of profiles in each cellular compartment was expressed as a percentage of the labeled profiles counted in all sampled hippocampal areas and all cellular compartments. In CA1 stratum oriens ( $\boldsymbol{A})$ and CA1 stratum lacunosum-moleculare $(\boldsymbol{D})$, there is no change in the distribution of pTrkB-ir across the estrous cycle or between sexes. In proximal $C A 1$ stratum radiatum $(\boldsymbol{B})$, proestrus females have significantly more $p$ TrkB-labeled glia than estrus females and diestrus males. ${ }^{*} p<0.05$ relative to estrus females and diestrus males. In distal CA1 stratum radiaum $(\boldsymbol{C})$, proestrus females have significantly more $\mathrm{pTrkB}$-labeled axons than estrus and diestrus females and males. ${ }^{*} p<0.05$ relative to all other groups. $N=3$.

gests that TrkB does not modulate inhibitory connections in the hippocampus.

\section{pTrkB is positioned to regulate glial function}

The abundance of pTrkB labeling in glial profiles was surprising, given that expression of the full-length TrkB receptor has not previously been described in these cells in vivo. In follow-up experiments, pTrkB colocalized with hippocampal microglia, but not astrocytes. TrkB ligands such as BDNF may therefore participate in immune functions in the brain, such as brain inflammation, through direct action on microglial TrkB receptors. An upregulation of BDNF has been identified in cases of central and peripheral inflammation or autoimmunity, but its role in these immune processes is unclear (Groth and Aanonsen, 2002; Linker et al., 2009). Further investigation of the function of microglial TrkB receptors will likely uncover novel mechanisms for neurotrophin regulation of the neuroimmune response.

\section{Interaction between estradiol and TrkB:}

functional considerations

In the current study, the proportion of pTrkB-ir in glia and axons in the CA1 stratum radiatum increased during proestrus. These changes likely contributed to the increase in pTrkB found in this hippocampal lamina during proestrus seen in our previous light microscope study (Spencer et al., 2008b).
Estradiol may increase TrkB phosphorylation by several different mechanisms. Estradiol enhances BDNF expression and release, which could increase TrkB activation in proportion to BDNF availability (Scharfman et al., 2003, 2007; Sato et al., 2007; Spencer et al., 2010). Estradiol also enhances retrograde transport of BDNF, which could directly increase TrkB activation in axons (Jezierski and Sohrabji, 2003). Additionally, estradiol may affect TrkB signaling indirectly by augmenting calcium influx (Wu et al., 2005; Zhao et al., 2005). Such increases in neuronal activity rapidly enhance TrkB insertion into the membrane, kinase activity, and $\mathrm{p} \operatorname{TrkB}$ endocytosis (Du et al., 2000, 2003). Finally, estradiol could transactivate TrkB via a GPCR such as the novel estrogen receptor GPR30 (Rajagopal and Chao, 2006; Hammond and Gibbs, 2011).

The CA1 stratum radiatum contains Schaffer collateral axons of CA3 pyramidal cells, which synapse on CA1 pyramidal cell dendrites in the stratum radiatum. These synapses are the most well characterized site of hippocampal LTP (Kerchner and Nicoll, 2008), and TrkB activation at these synapses is crucial for LTP and hippocampal-dependent associative learning (Gruart et al., 2007). These synapses are also particularly sensitive to estradiol, which increases dendritic spine density and synaptic potentiation in CA1 stratum radiatum (Woolley et al., 1990; Warren et al., 1995; Li et al., 2004). The increase in pTrkB-ir in axons of the CA1 stratum radiatum during proestrus suggests a novel role for axonal TrkB in these effects of estradiol. Axonal TrkB activation could increase the availability of synaptic contacts, facilitating an estradiol-dependent increase in postsynaptic dendritic spine density or size. Estradiol may have additional effects on axonal growth that so far have not been described in the hippocampal formation. Indeed, in the hypothalamus, estradiol increases axonal growth through a TrkB-dependent mechanism (Carrer et al., 2003; Brito et al., 2004).

Glia have received little attention as possible players in estradiol effects on the hippocampal formation. TrkB signaling in glia in CA1 stratum radiatum theoretically may be important for estradiol to increase dendritic spine density, as astrocytes have been shown to regulate spine maturation (Nishida and Okabe, 2007). Indeed, estrogen receptors $\alpha$ and $\beta$ are expressed in glia in the mouse hippocampus (Mitterling et al., 2010), implying that these cells can respond directly to estradiol. Evidence for this was presented in an in vitro study, where conditioned media from astrocytes exposed to estradiol protected neurons against $\beta$-amyloid-induced death (Sortino et al., 2004). The current study presents the first evidence of a link between estradiol and TrkB in glia, showing an increase in $\mathrm{pTrkB}$-ir in glial profiles in CA1 stratum radiatum during proestrus. The glia containing $\mathrm{p}$ TrkB-ir in this study colocalized with microglial, but not astrocytic, markers. This suggests a novel role for microglia in estradiol effects in hippocampus that will be an interesting area for future study. 


\section{Sex differences in the distribution of $p$ TrkB may reflect the influence of estradiol}

The behavioral effects of BDNF reduction in mice differ significantly in males and females; some of these differences can be explained by the presence or absence of estradiol (Monteggia et al., 2006; RenPatterson et al., 2006). In keeping with this idea, hippocampal BDNF expression is low in males and low-estradiol females compared with proestrus females (Scharfman et al., 2003). In the current study, the distribution of pTrkB-ir in male mice resembled that of low-estradiol (estrus or diestrus) females. Thus, estradiol likely mediates sex differences in BDNF/TrkB signaling by increasing $\mathrm{BDNF}$ expression and TrkB activation. This idea is potentially clinically important, as several common psychiatric disorders are associated with reductions in BDNF signaling (Buckley et al., 2007; Schmidt and Duman, 2007; Kapczinski et al., 2008).

\section{Conclusions}

This localization of $\mathrm{pTrkB}$ in the mouse hippocampal formation shows TrkB positioned to carry out local effects of BDNF in synapses and neurites, and more sustained effects via retrograde transport and activation of gene transcription. Extensive TrkB phosphorylation in microglia suggests a novel role for this neurotrophin receptor in the immune system in the brain. The majority of pTrkB-ir was found in neuronal axons and terminals. This presynaptic pTrkB-ir, as well as glial pTrkB-ir, increased in the CA1 stratum radiatum during the high-estradiol cycle phase, proestrus. This finding implicates presynaptic and glial TrkB in the synaptic plasticity mediated by BDNF and estradiol in the hippocampus.

\section{References}

Alderson RF, Curtis R, Alterman AL, Lindsay RM, DiStefano PS (2000) Truncated TrkB mediates the endocytosis and release of BDNF and neurotrophin- $4 / 5$ by rat astrocytes and Schwann cells in vitro. Brain Res 871:210-222.

Alsina B, Vu T, Cohen-Cory S (2001) Visualizing synapse formation in arborizing optic axons in vivo: dynamics and modulation by BDNF. Nat Neurosci 4:1093-1101.

Bath KG, Mandairon N, Jing D, Rajagopal R, Kapoor R, Chen ZY, Khan T, Proenca CC, Kraemer R, Cleland TA, Hempstead BL, Chao MV, Lee FS (2008) Variant brain-derived neurotrophic factor (Val66Met) alters adult olfactory bulb neurogenesis and spontaneous olfactory discrimination. J Neurosci 28:2383-2393.

Bhattacharyya A, Watson FL, Bradlee TA, Pomeroy SL, Stiles CD, Segal RA (1997) Trk receptors function as rapid retrograde signal carriers in the adult nervous system. J Neurosci 17:7007-7016.

Brito VI, Carrer HF, Cambiasso MJ (2004) Inhibition of tyrosine kinase receptor type B synthesis blocks axogenic effect of estradiol on rat hypothalamic neurones in vitro. Eur J Neurosci 20:331-337.

Buckley PF, Mahadik S, Pillai A, Terry A Jr (2007) Neurotrophins and schizophrenia. Schizophr Res 94:1-11.

Carim-Todd L, Bath KG, Fulgenzi G, Yanpallewar S, Jing D, Barrick CA, Becker J, Buckley H, Dorsey SG, Lee FS, Tessarollo L (2009) Endogenous truncated TrkB.T1 receptor regulates neuronal complexity and TrkB kinase receptor function in vivo. J Neurosci 29:678-685.

Carrer HF, Cambiasso MJ, Brito V, Gorosito S (2003) Neurotrophic factors and estradiol interact to control axogenic growth in hypothalamic neurons. Ann N Y Acad Sci 1007:306-316.

Chan J, Aoki C, Pickel VM (1990) Optimization of differential immunogoldsilver and peroxidase labeling with maintenance of ultrastructure in brain sections before plastic embedding. J Neurosci Methods 33:113-127.

Chan JP, Unger TJ, Byrnes J, Rios M (2006) Examination of behavioral deficits triggered by targeting Bdnf in fetal or postnatal brains of mice. Neuroscience 142:49-58.

Chao MV (2003) Neurotrophins and their receptors: a convergence point for many signalling pathways. Nat Rev Neurosci 4:299-309.

Chen LY, Rex CS, Sanaiha Y, Lynch G, Gall CM (2010) Learning induces neurotrophin signaling at hippocampal synapses. Proc Natl Acad Sci U S A 107:7030-7035.

Chen ZY, Ieraci A, Tanowitz M, Lee FS (2005) A novel endocytic recycling signal distinguishes biological responses of Trk neurotrophin receptors. Mol Biol Cell 16:5761-5772.

Conner JM, Lauterborn JC, Yan Q, Gall CM, Varon S (1997) Distribution of brain-derived neurotrophic factor (BDNF) protein and mRNA in the normal adult rat CNS: evidence for anterograde axonal transport. J Neurosci 17:2295-2313.

Cosker KE, Courchesne SL, Segal RA (2008) Action in the axon: generation and transport of signaling endosomes. Curr Opin Neurobiol 18:270-275.

Drake CT, Milner TA, Patterson SL (1999) Ultrastructural localization of full-length TrkB immunoreactivity in rat hippocampus suggests multiple roles in modulating activity-dependent synaptic plasticity. J Neurosci 19:8009-8026.

Drake CT, Chavkin C, Milner TA (2007) Opioid systems in the dentate gyrus. In: Progress in brain res (Scharfman H, ed), pp 245-264. Amsterdam: Elsevier.

Du J, Feng L, Yang F, Lu B (2000) Activity- and Ca(2+)-dependent modulation of surface expression of brain-derived neurotrophic factor receptors in hippocampal neurons. J Cell Biol 150:1423-1434.

Du J, Feng L, Zaitsev E, Je HS, Liu XW, Lu B (2003) Regulation of TrkB receptor tyrosine kinase and its internalization by neuronal activity and Ca2 + influx. J Cell Biol 163:385-395.

Gomes RA, Hampton C, El-Sabeawy F, Sabo SL, McAllister AK (2006) The dynamic distribution of TrkB receptors before, during, and after synapse formation between cortical neurons. J Neurosci 26:11487-11500.

Good M, Day M, Muir JL (1999) Cyclical changes in endogenous levels of oestrogen modulate the induction of LTD and LTP in the hippocampal CA1 region. Eur J Neurosci 11:4476-4480.

Groth R, Aanonsen L (2002) Spinal brain-derived neurotrophic factor (BDNF) produces hyperalgesia in normal mice while antisense directed against either BDNF or TrkB, prevent inflammation-induced hyperalgesia. Pain 100:171-181.

Gruart A, Sciarretta C, Valenzuela-Harrington M, Delgado-García JM, Minichiello L (2007) Mutation at the TrkB PLCgamma-docking site affects hippocampal LTP and associative learning in conscious mice. Learn Mem 14:54-62.

Hammond R, Gibbs RB (2011) GPR30 is positioned to mediate estrogen effects on basal forebrain cholinergic neurons and cognitive performance. Brain Res 1379:53-60.

Heldt SA, Stanek L, Chhatwal JP, Ressler KJ (2007) Hippocampus-specific deletion of BDNF in adult mice impairs spatial memory and extinction of aversive memories. Mol Psychiatry 12:656-670.

Horch HW (2004) Local effects of BDNF on dendritic growth. Rev Neurosci 15:117-129.

Horch HW, Katz LC (2002) BDNF release from single cells elicits local dendritic growth in nearby neurons. Nat Neurosci 5:1177-1184.

Hsu SM, Raine L (1981) Protein A, avidin, and biotin in immunohistochemistry. J Histochem Cytochem 29:1349-1353.

Jezierski MK, Sohrabji F (2003) Estrogen enhances retrograde transport of brain-derived neurotrophic factor in the rodent forebrain. Endocrinology 144:5022-5029.

Ji Y, Pang PT, Feng L, Lu B (2005) Cyclic AMP controls BDNF-induced TrkB phosphorylation and dendritic spine formation in mature hippocampal neurons. Nat Neurosci 8:164-172.

Jia JM, Chen Q, Zhou Y, Miao S, Zheng J, Zhang C, Xiong ZQ (2008) Brainderived neurotrophic factor-tropomyosin-related kinase $\mathrm{B}$ signaling contributes to activity-dependent changes in synaptic proteins. J Biol Chem 283:21242-21250.

Kang H, Schuman EM (1995) Long-lasting neurotrophin-induced enhancement of synaptic transmission in the adult hippocampus. Science 267:1658-1662.

Kapczinski F, Frey BN, Kauer-Sant'Anna M, Grassi-Oliveira R (2008) Brain-derived neurotrophic factor and neuroplasticity in bipolar disorder. Expert Rev Neurother 8:1101-1113.

Kerchner GA, Nicoll RA (2008) Silent synapses and the emergence of a postsynaptic mechanism for LTP. Nat Rev Neurosci 9:813-825.

Korol DL, Malin EL, Borden KA, Busby RA, Couper-Leo J (2004) Shifts in preferred learning strategy across the estrous cycle in female rats. Horm Behav 45:330-338.

Levine ES, Dreyfus CF, Black IB, Plummer MR (1996) Selective role for trkB 
neurotrophin receptors in rapid modulation of hippocampal synaptic transmission. Brain Res Mol Brain Res 38:300-303.

Li C, Brake WG, Romeo RD, Dunlop JC, Gordon M, Buzescu R, Magarinos AM, Allen PB, Greengard P, Luine V, McEwen BS (2004) Estrogen alters hippocampal dendritic spine shape and enhances synaptic protein immunoreactivity and spatial memory in female mice. Proc Natl Acad Sci U S A 101:2185-2190.

Linker R, Gold R, Luhder F (2009) Function of neurotrophic factors beyond the nervous system: inflammation and autoimmune demyelination. Crit Rev Immunol 29:43-68.

Luikart BW, Zhang W, Wayman GA, Kwon CH, Westbrook GL, Parada LF (2008) Neurotrophin-dependent dendritic filopodial motility: a convergence on PI3K signaling. J Neurosci 28:7006-7012.

Magby JP, Bi C, Chen ZY, Lee FS, Plummer MR (2006) Single-cell characterization of retrograde signaling by brain-derived neurotrophic factor. J Neurosci 26:13531-13536.

Martínez A, Alcántara S, Borrell V, Del Río JA, Blasi J, Otal R, Campos N, Boronat A, Barbacid M, Silos-Santiago I, Soriano E (1998) TrkB and TrkC signaling are required for maturation and synaptogenesis of hippocampal connections. J Neurosci 18:7336-7350.

Messaoudi E, Ying SW, Kanhema T, Croll SD, Bramham CR (2002) Brainderived neurotrophic factor triggers transcription-dependent, late phase long-term potentiation in vivo. J Neurosci 22:7453-7461.

Milner TA, Lee A, Aicher SA, Rosin DL (1998) Hippocampal alpha2aadrenergic receptors are located predominantly presynaptically but are also found postsynaptically and in selective astrocytes. J Comp Neurol 395:310-327.

Milner TA, McEwen BS, Hayashi S, Li CJ, Reagan LP, Alves SE (2001) Ultrastructural evidence that hippocampal alpha estrogen receptors are located at extranuclear sites. J Comp Neurol 429:355-371.

Minichiello L (2009) TrkB signalling pathways in LTP and learning. Nat Rev Neurosci 10:850-860.

Minichiello L, Korte M, Wolfer D, Kühn R, Unsicker K, Cestari V, RossiArnaud C, Lipp HP, Bonhoeffer T, Klein R (1999) Essential role for TrkB receptors in hippocampus-mediated learning. Neuron 24:401-414.

Mitterling KL, Spencer JL, Dziedzic N, Shenoy S, McCarthy K, Waters EM, McEwen BS, Milner TA (2010) Cellular and subcellular localization of estrogen and progestin receptor immunoreactivities in the mouse hippocampus. J Comp Neurol 518:2729-2743.

Miyamoto Y, Yamauchi J, Tanoue A, Wu C, Mobley WC (2006) TrkB binds and tyrosine-phosphorylates Tiam1, leading to activation of Rac1 and induction of changes in cellular morphology. Proc Natl Acad Sci U S A 103:10444-10449.

Mizuno M, Yamada K, He J, Nakajima A, Nabeshima T (2003a) Involvement of BDNF receptor TrkB in spatial memory formation. Learn Mem 10:108-115.

Mizuno M, Yamada K, Takei N, Tran MH, He J, Nakajima A, Nawa H, Nabeshima T (2003b) Phosphatidylinositol 3-kinase: a molecule mediating BDNF-dependent spatial memory formation. Mol Psychiatry 8:217-224.

Monteggia LM, Barrot M, Powell CM, Berton O, Galanis V, Gemelli T, Meuth S, Nagy A, Greene RW, Nestler EJ (2004) Essential role of brain-derived neurotrophic factor in adult hippocampal function. Proc Natl Acad Sci U S A 101:10827-10832.

Monteggia LM, Luikart B, Barrot M, Theobold D, Malkovska I, Nef S, Parada LF, Nestler EJ (2006) Brain-derived neurotrophic factor conditional knockouts show gender differences in depression-related behaviors. Biol Psychiatry 61:187-197.

Niewiadomska G, Mietelska-Porowska A, Mazurkiewicz M (2010) The cholinergic system, nerve growth factor and the cytoskeleton. Behav Brain Res. Advance online publication. doi:10.1016/j.bbr.2010.02.024.

Nishida H, Okabe S (2007) Direct astrocytic contacts regulate local maturation of dendritic spines. J Neurosci 27:331-340.

Ohira K, Kumanogoh H, Sahara Y, Homma KJ, Hirai H, Nakamura S, Hayashi M (2005) A truncated tropomyosin-related kinase B receptor, T1, regulates glial cell morphology via Rho GDP dissociation inhibitor 1 . J Neurosci 25:1343-1353.

Ohira K, Funatsu N, Homma KJ, Sahara Y, Hayashi M, Kaneko T, Nakamura S (2007) Truncated TrkB-T1 regulates the morphology of neocortical layer I astrocytes in adult rat brain slices. Eur J Neurosci 25:406-416.

Peters A, Palay SL, Webster Hd (1991) The fine structure of the nervous system: neurons and their supporting cells, 3rd Edition. New York: Oxford UP.

Rajagopal R, Chao MV (2006) A role for Fyn in Trk receptor transactivation by G-protein-coupled receptor signaling. Mol Cell Neurosci 33:36-46.

Ren-Patterson RF, Cochran LW, Holmes A, Lesch KP, Lu B, Murphy DL (2006) Gender-dependent modulation of brain monoamines and anxiety-like behaviors in mice with genetic serotonin transporter and BDNF deficiencies. Cell Mol Neurobiol 26:755-780.

Rex CS, Lin CY, Kramár EA, Chen LY, Gall CM, Lynch G (2007) Brainderived neurotrophic factor promotes long-term potentiation-related cytoskeletal changes in adult hippocampus. J Neurosci 27:3017-3029.

Roback JD, Marsh HN, Downen M, Palfrey HC, Wainer BH (1995) BDNFactivated signal transduction in rat cortical glial cells. Eur J Neurosci $7: 849-862$.

Rose CR, Blum R, Pichler B, Lepier A, Kafitz KW, Konnerth A (2003) Truncated TrkB-T1 mediates neurotrophin-evoked calcium signalling in glia cells. Nature 426:74-78.

Sandstrom NJ, Williams CL (2004) Spatial memory retention is enhanced by acute and continuous estradiol replacement. Horm Behav 45:128-135.

Sato K, Akaishi T, Matsuki N, Ohno Y, Nakazawa K (2007) beta-Estradiol induces synaptogenesis in the hippocampus by enhancing brain-derived neurotrophic factor release from dentate gyrus granule cells. Brain Res 1150:108-120.

Scharfman HE (1997) Hyperexcitability in combined entorhinal/hippocampal slices of adult rat after exposure to brain-derived neurotrophic factor. J Neurophysiol 78:1082-1095.

Scharfman HE, Maclusky NJ (2005) Similarities between actions of estrogen and BDNF in the hippocampus: coincidence or clue? Trends Neurosci 28:79-85.

Scharfman HE, Maclusky NJ (2006) Estrogen and brain-derived neurotrophic factor (BDNF) in hippocampus: complexity of steroid hormone-growth factor interactions in the adult CNS. Front Neuroendocrinol 27:415-435.

Scharfman HE, Mercurio TC, Goodman JH, Wilson MA, MacLusky NJ (2003) Hippocampal excitability increases during the estrous cycle in the rat: a potential role for brain-derived neurotrophic factor. J Neurosci 23:11641-11652.

Scharfman HE, Hintz TM, Gomez J, Stormes KA, Barouk S, MalthankarPhatak GH, McCloskey DP, Luine VN, Maclusky NJ (2007) Changes in hippocampal function of ovariectomized rats after sequential low doses of estradiol to simulate the preovulatory estrogen surge. Eur J Neurosci 26:2595-2612.

Schmidt HD, Duman RS (2007) The role of neurotrophic factors in adult hippocampal neurogenesis, antidepressant treatments and animal models of depressive-like behavior. Behav Pharmacol 18:391-418.

Sierra A, Gottfried-Blackmore A, Milner TA, McEwen BS, Bulloch K (2008) Steroid hormone receptor expression and function in microglia. Glia 56:659-674.

Sortino MA, Chisari M, Merlo S, Vancheri C, Caruso M, Nicoletti F, Canonico PL, Copani A (2004) Glia mediates the neuroprotective action of estradiol on beta-amyloid-induced neuronal death. Endocrinology 145:5080-5086.

Spencer JL, Waters EM, Milner TA, McEwen BS (2008a) Estrous cycle regulates activation of hippocampal Akt, LIM kinase, and neurotrophin receptors in C57BL/6 mice. Neuroscience 155:1106-1119.

Spencer JL, Waters EM, Romeo RD, Wood GE, Milner TA, McEwen BS (2008b) Uncovering the mechanisms of estrogen effects on hippocampal function. Front Neuroendocrinol 29:219-237.

Spencer JL, Waters EM, Milner TA, Lee FS, McEwen BS (2010) BDNF variant Val66Met interacts with estrous cycle in the control of hippocampal function. Proc Natl Acad Sci U S A 107:4395-4400.

Svingos AL, Colago EE, Pickel VM (1999) Cellular sites for dynorphin activation of kappa-opioid receptors in the rat nucleus accumbens shell. J Neurosci 19:1804-1813.

Thakker-Varia S, Alder J, Crozier RA, Plummer MR, Black IB (2001) Rab3A is required for brain-derived neurotrophic factor-induced synaptic plasticity: transcriptional analysis at the population and single-cell levels. J Neurosci 21:6782-6790.

Turner CD, Bagnara JT (1971) General endocrinology, 5th Edition. Philadelphia: Saunders. 
Tyler WJ, Pozzo-Miller LD (2001) BDNF enhances quantal neurotransmitter release and increases the number of docked vesicles at the active zones of hippocampal excitatory synapses. J Neurosci 21:4249-4258.

Warren SG, Humphreys AG, Juraska JM, Greenough WT (1995) LTP varies across the estrous cycle: enhanced synaptic plasticity in proestrus rats. Brain Res 703:26-30.

Watson FL, Heerssen HM, Moheban DB, Lin MZ, Sauvageot CM, Bhattacharyya A, Pomeroy SL, Segal RA (1999) Rapid nuclear responses to targetderived neurotrophins require retrograde transport of ligand-receptor complex. J Neurosci 19:7889-7900.

Wiedemann FR, Siemen D, Mawrin C, Horn TF, Dietzmann K (2006) The neurotrophin receptor TrkB is colocalized to mitochondrial membranes. Int J Biochem Cell Biol 38:610-620.

Woolley CS, Gould E, Frankfurt M, McEwen BS (1990) Naturally occurring fluctuation in dendritic spine density on adult hippocampal pyramidal neurons. J Neurosci 10:4035-4039.

Wu TW, Wang JM, Chen S, Brinton RD (2005) 17Beta-estradiol induced $\mathrm{Ca} 2+$ influx via L-type calcium channels activates the Src/ERK/cyclic-
AMP response element binding protein signal pathway and BCL-2 expression in rat hippocampal neurons: a potential initiation mechanism for estrogen-induced neuroprotection. Neuroscience 135:59-72.

Yan Q, Radeke MJ, Matheson CR, Talvenheimo J, Welcher AA, Feinstein SC (1997) Immunocytochemical localization of TrkB in the central nervous system of the adult rat. J Comp Neurol 378:135-157.

Zhang J, Geula C, Lu C, Koziel H, Hatcher LM, Roisen FJ (2003) Neurotrophins regulate proliferation and survival of two microglial cell lines in vitro. Exp Neurol 183:469-481.

Zhao L, Chen S, Ming Wang J, Brinton RD (2005) 17beta-estradiol induces $\mathrm{Ca} 2+$ influx, dendritic and nuclear $\mathrm{Ca} 2+$ rise and subsequent cyclic AMP response element-binding protein activation in hippocampal neurons: a potential initiation mechanism for estrogen neurotrophism. Neuroscience 132:299-311.

Zheng J, Shen WH, Lu TJ, Zhou Y, Chen Q, Wang Z, Xiang T, Zhu YC, Zhang C, Duan S, Xiong ZQ (2008) Clathrin-dependent endocytosis is required for TrkB-dependent Akt-mediated neuronal protection and dendritic growth. J Biol Chem 283:13280-13288. 